\title{
The Shock Reaction in a Simple Close Economy
}

\author{
ADIREK VAJRAPATKUL School of Economics, \\ Sukhothai Thammathirat Open University, \\ Chaengwattana Rd. Bangpood, Pakkret Nonthaburi 11120, \\ THAILAND
}

\begin{abstract}
As the general objective of a representative government is to achieve in creating the economic conditions that support the wellbeing of citizen, it, thus, needs to design and implement its policies in an appropriated manner. Hence, to support the valuable information for designing and implementing such policies, this work is designed to gain that information by trying to identify the reactions of various variables to government policies. To meet this objective, this work proposed a simple close economy Dynamic stochastic general equilibrium (DSGE) model with the public goods in the household consumption bundle. Also, the usual shocks studied in the DSGE model were included in the reaction investigation process. The Bayesian technique is then employed to estimate the model parameters by using the quarterly detrended data of Thailand in the period of 2001 to 2019. The result showed the crowding-out effect driven by government spending. Also, the reactions of the major macroeconomic variables to each shock were consistent with some previous studies.
\end{abstract}

Key-words: DSGE, Close Economy, monetary policy, fiscal policy, Bayesian Estimation

Received: January 27, 2021. Revised: May 9, 2021. Accepted: May 26, 2021. Published: June 7, 2021.

\section{Introduction}

Government is a representative economic agent that acts to control the country's economy such that it is in the conditions that promise the citizen wellbeing. This agent normally uses two major instruments, namely monetary and fiscal policies, to achieve that objective. However, these instruments can be used effectively only when they are designed and implemented in the right manner. In this regard, sufficient information relevance to these two instruments, e.g. their effects on the target variables and economy, needs to be identified and used in the policy design and implementation process. Nevertheless, having such information is not a simple task as the results produced from monetary and fiscal policies can be varied and are sensitive to the variation of policy characteristics and environmental attributes under consideration. This informs us that if the government launch a new marginally adjusted policy in a particular economic circumstance, it will probably experience new unexpected results. Similarly, even though, it launches the same old policy in a new economic 
environment, it will probably discover the new unexpected results as well.

To learn the effects of those policies, scholars have employed several techniques. An important technique that the scholars have used for this purpose is Dynamic Stochastic General Equilibrium (DSGE) model. This model allows the scholars, especially, to investigate the interaction between policy initiations and variables within the economic environment. The major advantage of this model is that it facilitates the cooperation of several assumptions in the analysis and thus leads to opportunities for applications in many circumstances. For instance, the scholars assumed some anomaly phenomena, e.g., changing of preference, technology, and risk in the model and then investigated the results produced by monetary and fiscal policy.

With monetary policy analysis, the major task of DSGE model, several works have tried to explore the effects of this policy intervention in the economy. The results from some of those works showed that, e.g., the marginal cost [1], work hours, investment [2,3], consumption, inflation, and output [4 - 6] reacted negatively to a positive monetary policy shock. However, the reactions of those variables to this policy shock are condition-specific issues [6]. Therefore, when the analysts change the model assumption, they should expect to see a unique reaction of the variables to the monetary policy shock.

In fiscal policy analysis, which is the primary aim of this work, there is a puzzle in the results of the model simulation, in particular, there are the inconclusive outcomes of the effects of government spending [7]. Regarding the private spending there incur the three probable outcomes of government spending which are positive (crowding-in), negative (crowding-out), and neutral outcome which can be learned in $[8,9]$. For household consumption, its reactions to government spending is depended on, e.g., the methods of financing for government spending, the functional form of household utility, and other related assumptions used in the analysis [10]. For instance, some scholars imposed particular assumptions to allow household consumption to increase when facing with government budget deficit policy by, e.g., using the nonseparable preferences, choosing parameters to satisfy a type of good, i.e., an inferior good, setting particular sufficient conditions [11], and designing the utility function which satisfies the complementarity relationship between public and private consumption [12]. Also, some scholars designed the model to reflect the nonRicardian type of households which save nothing but consume all their current disposable income and hence when there incur the government spending shock, the level of consumption of such household would positively response [13]. Similarly, the assumptions about the consumption habits, the complementarity between consumption and hours worked, and the initial conditions using in the analysis can support a positive reaction of consumption to government spending [14]. In contrast, it is possible that government spending can reduce household consumption if government subsidize its budget deficit by raising tax $[11,15,16]$. Sometimes, government spending made the output rise but drove private consumption down [17].

Motivated by the outcomes of monetary and fiscal policies discussed above, this work is hence designed to learn some potential outcomes of such policies in the hypothesized economy embedded with public goods by using the simple close economy DSGE model with the Bayesian estimation techniques. It will include the usual shock of the consumption preference and technology in this analysis. To meet this objective, this work will be organized as follows. The next section will discuss the theoretical perspective related to the effect of monetary policy and fiscal policy on economy. Section 3 will derive the model that is subsequently estimated. Section 4 will describe the data used for model estimation. In section 5 , the model will be estimated. Finally, the result of the analysis will be shortly discussed in Section 6.

\section{Theoretical Perspective of The Effect Of Monetary Policy and Fiscal Policy on Economy}

This section will highlight the role of monetary and fiscal policies in stabilizing the economy 
and their effects on economy, which will be useful for understanding the dynamics of macroeconomic variables within the economy. The concepts discussed in this section are derived from [18 - 20].

Let begin with the monetary policy conducted by the central bank to combat the economic overgrowth and undergrowth situation. Regarding this policy, the central bank can control the economy to rest in the expected equilibrium by using the monetary policy tools to optimize the interest rate and inflation. When the central change the policy rate, it can produce an effect on both the market short-term interest rate and money supply. By changing the policy rate or the overnight loan rate, the short-term security rate will be changed, which will further affect other market short-term rates. Also, the money supply can be changed after the changing of policy rate as a result of the effect of policy rate on the level of bank reserve which determines the bank loan availability.

The effects of the changing in the policy rate are not only limit to that short-term rate and money supply but also pass-through to other macroeconomic variables, e.g., long-term real interest rate, consumption, saving, investment, and output. For the effect on the long-term interest rate, a fall in the policy rate that increases the supply of bank loans will reduce the equilibrium interest rate. This reduction of the interest rate will encourage consumption expenditure and investment. In case that household has only two choices of allocating their income, i.e., consuming and saving, an increase in consumption should mean a decrease in saving. However, what will happen to the aggregate demand will depend on the multiplier effect of consumption, investment, and saving generated after the changing of the policy rate.

To be specific, the effects of monetary policy can be separated into short-run and longrun effects. For the short-run effect, as already discussed, the reduction of the policy rate and increase of money supply will encourage consumption, investment, employment, and real output. However, the increasing of money supply also means inflation and reduction of real value and purchasing power of money in the long run. In the long run, after the prices of outputs and inputs are not sticky and completely adjusted, the short-run benefit of this monetary expansion will disappear. This is because the output and input price can affect the decisions of firms in the amount of output to be produced and workers to be employed. That is, in the long run, if the monetary expansion brings in inflation but aggregate demand, the short-run benefit of this policy will be vanished. Here, monetary policy does not affect real output or unemployment, but inflation.

The idea that the money supply does not affect real economic variables, according to the classical school of thought, is known as monetary neutrality. Nevertheless, Keynesian schools of thought still value the short-run effect of monetary policy in helping economy overcome the economic difficulties during economic recessions and smoothing out the business cycle.

The adjustments in expectations also supported the neutrality of monetary policy. That is when inflation is expected, the prices are planned to be adjusted in advance, and hence the effect of monetary policy will be limited, even in the short run. Therefore, the role of monetary policy in stabilizing the economy comes with limitations caused by monetary neutrality and expected behavior. Also, the effects of monetary policy are indirect and depended on how private decisions respond to a change in the interest rate. Moreover, the time lags in the operation of monetary policy are longer than those of fiscal policy. Hence, it needs a long-term perspective on this policy.

Now we will discuss on the fiscal policy which relies on government spending, tax, and transfer. Fiscal policy can affect both aggregate demand and aggregate supply. For the demandside effects of fiscal policy, when government increase its spending, the aggregate demand and real output are expected to be increased. When government decrease taxes, it will increase disposable income, which will further induce consumption and aggregate demand. For government transfer, an increase in transfer payments will increase disposable income, consumption, and hence aggregate demand. Although, government equalize its expenditure and income by using a balanced budget policy, 
it still makes aggregate demand and output increases because of the difference in the multiplier effects apply to government spending, tax, and transfer. Similar to monetary policy, the fiscal policy has both short-run and long-run effects. In the short run, fiscal stimulus achieved by increasing government spending, decreasing tax revenues, and raising government transfer can boost aggregate demand, real output, and employment. However, this situation brings a rise in the price level. So, in the long run, the effect of fiscal policy can be neutral as the case of monetary policy. For the supply-side effects, government expenditure and taxes can affect aggregate supply, e.g., when government increase its spending in public goods, services, and infrastructures, the productions will become more productive which support higher production possibility frontier which imply larger outputs and aggregate supply.

With taxes that affect incentives to work, save, and conduct entrepreneurial activities, when government raises taxes, e.g., on labor income, it will decrease labor supply and raise the real wage rate and thus reduce labor demand. With a low level of labor employed, the potential output and aggregate supply are decreased. Likewise, taxes on income from capital can decrease saving and supply of capital. A smaller supply of capital means higher real interest rate and lower investment and capital demand which will cause lesser in output and aggregate supply. Also, taxes on the incomes of entrepreneurs will weaken the incentive to take risks and create new businesses. With a small number of businesses, the quantities of labor and capital employed are decreased and thus potential output and aggregate supply will be decreased as well.

Like monetary policy, the fiscal policy faces shortcomings, especially the so-called crowding-out effect. The crowding-out occurs when private spending falls in responding to an increase in government spending. When private spending falls and the aggregate output doesn't increase as expected, the fiscal policy said to be ineffective. A plausible explanation for a reduction in private spending is that when government increases spending, with taxes unchanged, and borrow from the loanable funds market to subsidize its spending, the demand for loans will be increased. This increased demand will drive the interest rate up, which will in turn discourages private investment and consumption, while encourage private saving. This will consequently lead to the reduction of private spending.

\section{The Model}

In the following the model will be formulated based on the simple relationship between three representative agents, i.e., household, firm, and government.

\subsection{Households}

To present the role of the households in this setting economy, we assume that they try to maximize their lifetime utility by consuming both private and public goods. However, their utility is declined by working hours. To express this idea, the usual utility function [18-20] was adopted by imposing the government spending proxied by public good in the household consumption bundle [21-23] as follow

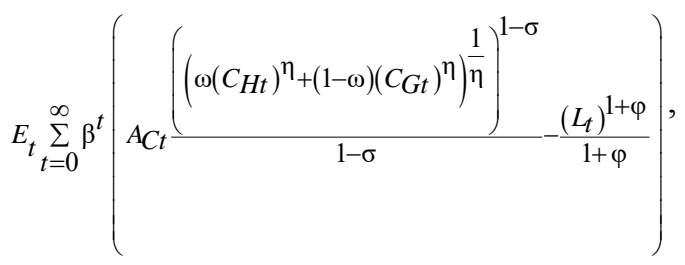

where the constant $\beta$ denotes the intertemporal discount factor, $\omega$ is the private good proportion in consumption bundle, $\eta$ expresses the elasticity of substitution between private and public good, $\sigma$ and $\varphi$ represent the inverse elasticity of consumption and the inverse elasticity of labor supply, respectively. The variable $C_{H t}$ is private goods, while $C_{G t}$ and $L_{t}$ denote, respectively, the public goods and working hours. The evolution of consumption is proxied by $A_{C t}$ which accounts for irregular changes in consumption [24] and moves according to the following first-order autoregressive process: 


$$
\begin{gathered}
\ln \left(A_{C, t}\right)=\left(1-\rho_{A C}\right) \ln \left(A_{C S s}\right)+\rho_{A C} \ln \left(A_{C, t-1}\right)+\varepsilon_{A C, t}, \\
\left|\rho_{A C}\right|<1, \varepsilon_{A C, t} \sim N\left(0, Q_{A C}\right) .
\end{gathered}
$$

The corresponding household budget constraint is assumed and expressed by the following equation:

$$
W_{t} N_{t}+R_{K, t} K_{t}+B_{t}+\Pi_{t}=P_{t}\left(C_{t}+I_{t}\right)+\frac{B_{t+1}}{R_{t}}+T_{t},(3)
$$

where $K_{t}$ is the capital, $B_{t}$ indicates the riskless one-period bonds, $\mathrm{Il}_{t}$ denotes profit, $I_{t}$ and $T_{t}$ are an investment and lump-sum tax. Also, $R_{t}, W_{t}, R_{K, t}$ represent policy rate, wage rate, and capital rental rate. by

The usual law of motion of capital is defined

$$
K_{t+1}=(1-\zeta) K_{t}+I_{t},
$$

where $\zeta$ is the capital depreciation rate.

The first-order condition of the household's problem provide

$$
\begin{aligned}
& { }^{\omega A} C_{C, t} W_{t}=L_{t}^{\varphi} C_{H, t}{ }^{1-\eta} P_{t}\left(\omega C_{H, t}{ }^{\eta}+(1-\omega) C_{G, t}^{\eta}\right)^{\frac{\eta+\sigma-1}{\eta}}, \\
& R_{K, t+1}+(1-\delta) P_{t+1}=\frac{P_{t+1}}{\beta} \frac{{ }^{A} C, t}{{ }_{C, t+1}}\left(\frac{C_{H, t+1}}{C_{H, t}}\right)^{1-\eta}, \\
& \left(\frac{\omega C_{H, t}{ }^{\eta}+(1-\omega) C_{G, t}^{\eta}}{\omega C_{H, t+1}{ }^{\eta}+(1-\omega) C_{G, t+1}^{\eta}}\right)^{\frac{1-\sigma-\eta}{\eta}} \\
& \left(\frac{\omega C_{H, t}{ }^{\eta}+(1-\omega) C_{G, t}^{\eta}}{\omega C_{H, t+1}{ }^{\eta}+(1-\omega) C_{G, t+1}^{\eta}}\right)^{\frac{1-\sigma-\eta}{\eta}} . \\
& =R_{t} \beta \frac{{ }_{C, t+1}}{{ }^{A} C, t} \frac{P_{t}}{P_{t+1}}\left(\frac{C_{H, t}}{C_{H, t+1}}\right)^{1-\eta}
\end{aligned}
$$

\subsection{Firms}

The crucial role of firms in this hypothesized economy can be expressed by the following Cobb-Douglas technology production function:

$$
Y_{t}=A_{T, t} K_{t}^{\alpha} L_{t}^{1-\alpha}
$$

where $\alpha$ represents the capital shared in the production and $A_{T, t}$ denotes the technology evolution characterized by the first-order autoregressive process.

The solutions to this problem are given by

$$
\begin{gathered}
W_{t} L_{t}=(1-\alpha) P_{t} Y_{t}, \\
R_{K, t} K_{t}=\alpha P_{t} Y_{t}, \\
P_{t}=\frac{1}{A_{T, t}}\left(\frac{W_{t}}{(1-\alpha)}\right)^{1-\alpha}\left(\frac{R_{K, t}}{\alpha}\right)^{\alpha} .
\end{gathered}
$$

\subsection{Fiscal authority}

In this economy, the fiscal authority assigns the budget for producing public goods, $C_{G, t}$ by taking into consideration the level of inflation and national income in the last periods $[25,26]$. Hence the rule for fiscal policy is written by:

$$
\frac{C_{G, t}}{C_{G s s}}=\left(\frac{C_{G, t-1}}{C_{G s s}}\right)^{\zeta} G\left(\frac{Y_{s s}}{Y_{t-1}} \frac{\pi_{s s}}{\pi_{t-1}}\right)^{\left(1-\zeta_{G}\right) \kappa_{G}}{ }_{A, t},
$$

Here, we assume that the monetary authority sets the policy rate, $R_{t}$ according to the following rule $[27,28]$ :

$$
\frac{R_{t}}{R_{S S}}=\left(\frac{R_{t-1}}{R_{s S}}\right)^{\zeta_{M}}\left(\left(\frac{Y_{t}}{Y_{s S}}\right)^{\kappa_{Y}}\left(\frac{\pi_{t}}{\pi_{s s}}\right)^{\kappa_{\pi}}\right)^{\left(1-\zeta_{M}\right)} A_{M, t},(
$$

where $A_{M, t}$ and $A_{G, t}$ denote a monetary and fiscal policy evolution that follows the firstorder autoregressive process. 


\subsection{Market clearing condition}

Since the goods produced in this economy are consumed and investment, we can present the market-clearing condition by the following equation

$$
Y_{t}=C_{H, t}+C_{G, t}+I_{t} .
$$

\subsection{Log-linear model}

The key log-linear form of the model can be written as follow

$$
\begin{aligned}
& \tilde{W}_{t}+\tilde{A}_{C, t}=\varphi \tilde{L}_{t}+(1-\eta) \tilde{C}_{H, t}+\tilde{P}_{t}+\left(1+\frac{\sigma}{\eta}-\frac{1}{\eta}\right), \\
& \left(\frac{\eta\left(\omega \tilde{C}_{H s s}^{\eta} \tilde{C}_{H, t}+(1-\omega) \tilde{C}_{G s s}^{\eta} \tilde{C}_{G, t}\right)}{\left(\omega C_{H s s}^{\eta}+(1-\omega) C_{G s s}^{\eta}\right)}\right) \\
& (1-\eta-\sigma)\left(\begin{array}{l}
\left(\frac{\eta\left(\omega C_{H s s}^{\eta} \tilde{c}_{H, t+1}+(1-\omega) C_{G s s}^{\eta} \tilde{c}_{G, t+1}\right)}{\left(\omega C_{H s s}^{\eta}+(1-\omega) C_{G s s}^{\eta}\right)}\right) \\
-\left(\frac{\eta\left(\omega C_{H s s}^{\eta} \tilde{c}_{H, t}+(1-\omega) C_{G s s}^{\eta} \tilde{C}_{G, t}\right)}{\left(\omega C_{H s s}^{\eta}+(1-\omega) C_{G s s}^{\eta}\right)}\right)
\end{array}\right) \\
& =\eta(\beta(\delta-1)+1) \tilde{P}_{t+1}+\eta(\beta(1-\delta)-1) \tilde{R}_{K, t+1} \\
& +\eta(1-\eta)\left(\tilde{C}_{H, t+1}-\tilde{C}_{H, t}\right)-\eta\left(\tilde{A}_{C, t+1}-\tilde{A}_{C, t}\right) \\
& (1-\eta-\sigma)\left(\begin{array}{l}
\left(\frac{\eta\left(\omega C_{H s s}^{\eta} \tilde{C}_{H, t+1}+(1-\omega) C_{G s s}^{\eta} \tilde{C}_{G, t+1}\right)}{\left(\omega C_{H s s}^{\eta}+(1-\omega) C_{G s s}^{\eta}\right)}\right) \\
-\left(\frac{\eta\left(\omega C_{H s s}^{\eta} \tilde{C}_{H, t}+(1-\omega) C_{G s s}^{\eta} \tilde{C}_{G, t}\right)}{\left(\omega C_{H s s}^{\eta}+(1-\omega) C_{G s s}^{\eta}\right)}\right)
\end{array}\right), \\
& =\eta\left(\tilde{t}_{t+1}-\tilde{P}_{t}\right)+\eta(1-\eta)\left(\tilde{C}_{H, t+1}-\tilde{C}_{H, t}\right) \\
& -\eta\left(\tilde{A}_{C, t+1}-\tilde{A}_{C, t}+\tilde{R}_{t}\right)
\end{aligned}
$$

$\tilde{W}_{t}+\tilde{L}_{t}=\tilde{P}_{t}+\tilde{Y}_{t}$,

$$
\tilde{R}_{K t}+\tilde{K}_{t}=\tilde{P}_{t}+\tilde{Y}_{t},
$$

$$
\tilde{P}_{t}=\alpha \tilde{R}_{K t}+\tilde{W}_{t}(1-\alpha)-\tilde{A}_{T, t},
$$$$
\tilde{C}_{G, t}=\zeta_{G} \tilde{C}_{G, t-1}-\left(1-\zeta_{G}\right) \kappa_{G}\left(\tilde{t}_{t-1}+\tilde{Y}_{t-1}\right)+\tilde{A}_{G, t},
$$$$
\tilde{R}_{t}=\zeta_{M} \tilde{R}_{t-1}+\left(1-\zeta_{M}\right)\left(\kappa_{\pi} \tilde{\pi}_{t}+\kappa_{Y} \tilde{Y}_{t}\right)+\tilde{A}_{M, t},
$$

$$
\tilde{Y}_{t}=\frac{I_{s s} \tilde{I}_{t}+C_{G s s} \tilde{C}_{G, t}+C_{H s s} \tilde{C}_{H, t}}{C_{H s s}+C_{G s s}+I_{s s}},
$$

\section{Data}

To estimate the model, we obtained the four series of quarterly data of Thailand covered the period between 2001:Q1-2019:Q2 from the World Bank database. The obtained data, i.e., GDP, policy rate, employment, and consumer price index, were then detrended [29]. Their dynamic can be observed in Figure 1.

YCYCLE

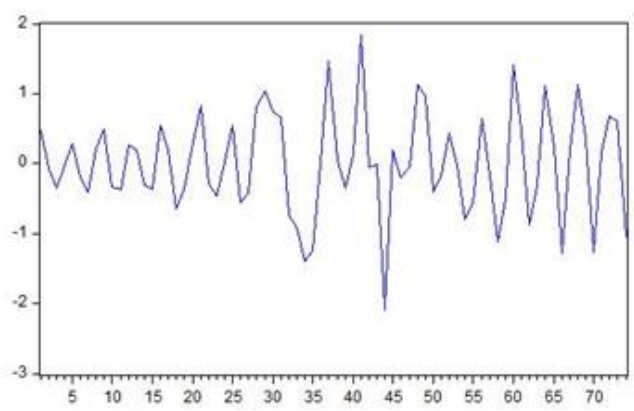

LCYCLE

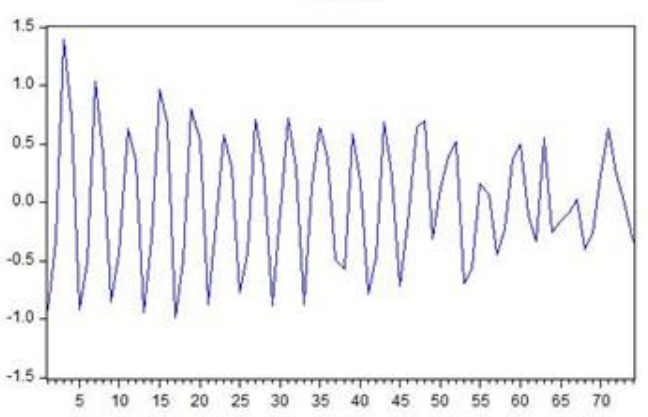

RCYCLE

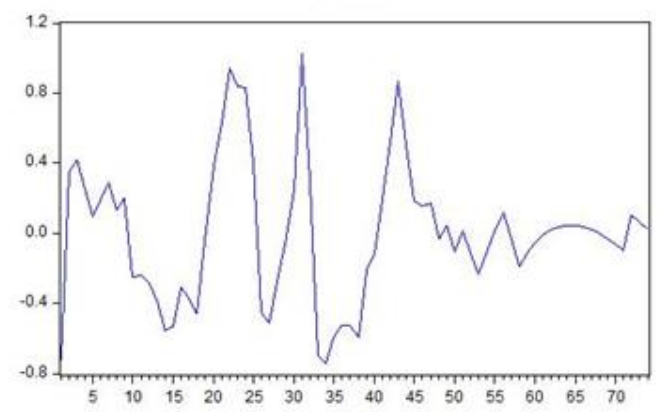




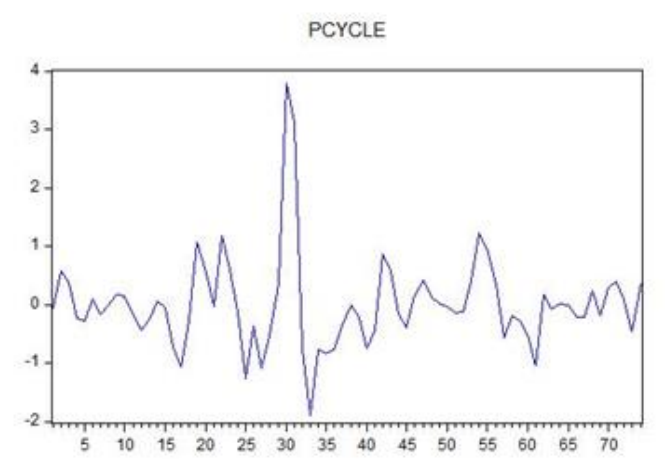

Figure1: The quarterly detrended data series of GDP, policy rate, employment, and CPI of Thailand.

\section{Bayesian Estimates}

To estimate DSGE models, scholars often employ Bayesian techniques [30], especially in the complexed models to impose some features of the data to the model. Based on this technique, the prior information will improve the accuracy of the estimated parameters. However, the value of those estimated parameters may be affected by the choice of priors and so it makes the difficulty for economic inference [31].

Also, Bayesian estimation allows analysts to deal with the issues of model misspecification and identification. In the parameter identifying process, Bayesian techniques try to derive the posterior distribution of those parameters with uncertainty recognition. The posterior density using for this purpose is of the following form

$$
p\left(\omega \mid y_{T}\right)=\frac{f\left(\omega \mid y_{T}\right) p(\omega)}{\int f\left(\omega \mid y_{T}\right) p(\omega) d \omega},
$$

where $\omega \in \Omega$ is the model parameters being estimated and $\Omega$ represent the parameter space. $y_{T}$ presents the set of observed data. $f\left(\omega \mid y_{T}\right)$ denotes the likelihood function assuming normal distribution of the disturbances. $P(\omega)$ represents the prior density. To derive the posterior density of the parameters, the candidate $\omega_{k}, k=0,1,2 \ldots$ are drawn from the Markov Chain Monte Carlo (MCMC) method. At each step $k$, the proposal density used to draw a new candidate parameter $\omega^{*}$ is a $N\left(\omega^{k}, c \Sigma\right)$ where $c$ is the scaling constant and $\Sigma$ is the variance-covariance matrix that is updated in the drawing iteration process.

$$
a=\min \left[1, \frac{f\left(y_{T} \mid \omega^{*}\right) q\left(\omega^{*}\right)}{f\left(y_{T} \mid \omega^{k}\right) q\left(\omega^{k}\right)}\right],
$$

where $q\left(\omega^{*}\right)$ is the density of the candidate parameter [33, 34].

For the estimation purpose, the prior distributions and means selected from the related literature were summarized in Table 2 . Because some parameters are estimated, the rest of them, shown in Table 1, will be set according to the values that are used in the relevant literature, i.e., the share of capital in production $\alpha$ is set to 0.3 . The depreciation rates for private capital $\delta$ is set to 0.011 , implying an annual depreciation of 4.4 percent.

Table 1: Calibrated parameters

\begin{tabular}{ccr}
\hline Para. & Value & \multicolumn{1}{c}{ Source } \\
\hline$\delta$ & 0.3 & Tanboon (2008) [34] \\
$\delta$ & 0.011 & Tanboon (2008) \\
$\zeta_{G}$ & 0.8 & Tanboon (2008) \\
$\zeta_{M}$ & 0.85 & Tanboon (2008) \\
$\rho_{A T}$ & 0.8 & Alp \& Elekdag (2012) [24] \\
$\rho_{A C}$ & 0.8 & Pytlarczyk (2005) [35] \\
\hline
\end{tabular}

The estimation results are represented in Table 2 and Figure 2. 
Table 2: Priors and posteriors of model parameters

\begin{tabular}{|c|c|c|c|c|c|}
\hline \multirow{2}{*}{$\begin{array}{c}\mathrm{Pa} \\
\mathrm{ra}\end{array}$} & \multicolumn{2}{|c|}{ Prior } & \multicolumn{3}{|c|}{ Posterior } \\
\hline & Distr. & Mean & Mean & $\begin{array}{c}\text { HPD } \\
\text { inf }\end{array}$ & $\begin{array}{l}\text { HPD } \\
\text { sup }\end{array}$ \\
\hline$\varphi$ & gamma & 3.00 & 2.94 & 2.86 & 3.02 \\
\hline$\eta$ & gamma & 1.00 & 1.00 & 0.93 & 1.07 \\
\hline$\sigma$ & gamma & 0.70 & 0.70 & 0.69 & 0.72 \\
\hline$\omega$ & gamma & 0.50 & 0.46 & 0.52 & 0.50 \\
\hline$\beta$ & gamma & 0.97 & 0.97 & 0.97 & 0.97 \\
\hline$\kappa_{G}$ & gamma & 0.20 & 0.21 & 0.19 & 0.22 \\
\hline$\kappa_{\pi}$ & gamma & 0.20 & 0.20 & 0.19 & 0.22 \\
\hline$\kappa_{Y}$ & gamma & 0.20 & 0.19 & 0.18 & 0.21 \\
\hline$\rho_{A G}$ & beta & 0.80 & 0.83 & 0.78 & 0.89 \\
\hline$\rho_{A M}$ & beta & 0.80 & 0.88 & 0.82 & 0.93 \\
\hline
\end{tabular}
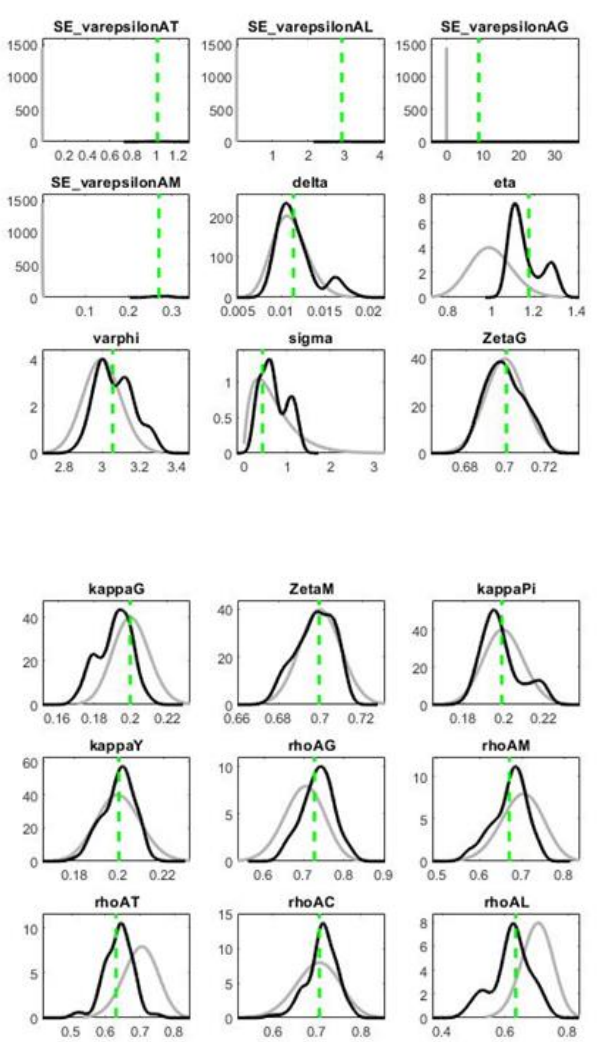

Figure 2: (a) Priors and posteriors.
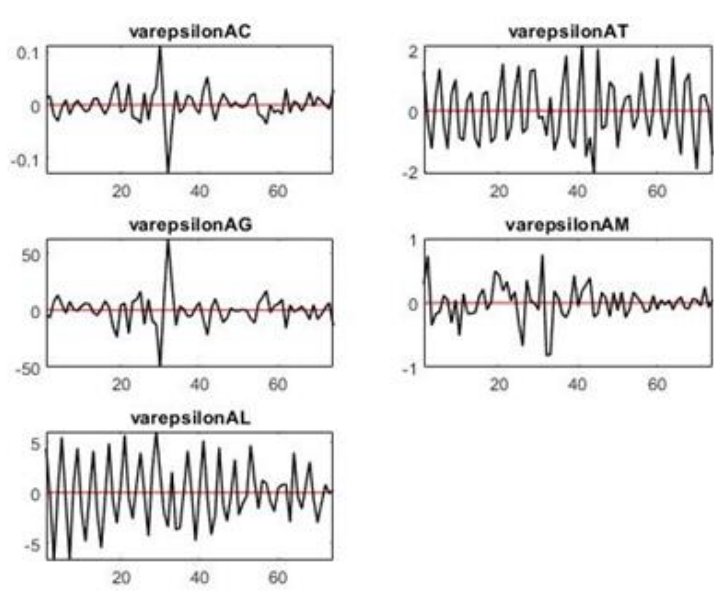

Figure 2: (b) Smoothed shock.

\section{Results}

This section will highlight the results discovered in this work. According to Figure 3, the shock on consumption preference can produce a positive effect on the consumption of private goods and a negative effect on the consumption of public goods. For the interest rate, it was adjusted to the price and national income and hence partially produce the effect on the level of investment. Because the overall consumption is enhanced, the national income is increased.

Refer to Figure 4 which represents the effect of a technology shock, it was discovered that when there is an improvement in technology, there occurs an increase in demand for the inputs of production but a decrease in the input price. Thereafter, the fall in the cost of production will support the reduction of price. Although the wage and return from renting capital are deceased, the benefit from increases in demand for labor and capital can support the rise of income and consumption. Since the public good is assumed to be a substituted good, it intends to fall after the household change their decision to consume more private one but it substantially increases as the output expanded which supported by the technology progression. The central bank reacts to the price by 
decreasing the interest rate and successively increase when price and national income increase. The interaction between each variable will continue until they back to their equilibrium if they do not persist at another place.

Figure 5 shows the reaction of the household to government spending or public goods shock. It can be observed that private consumption is decreased after public goods increase. Also, household investment is increased after such public good shock occurred. The fall of the overall consumption or demand brings down the price, wage, and capital rental rate. However, there are only negligible amounts of declining in the total consumption, which requires a short period for national income to recover and locate above its equilibrium, which indicates the positive effect of fiscal policy on economic growth.

Finally, the result of the monetary policy shock shown in Figure 6 will be shortly discussed. After the central bank raises the interest rate, the private good consumption, investment, price, and input price are decreased which lead to the fall of national income.
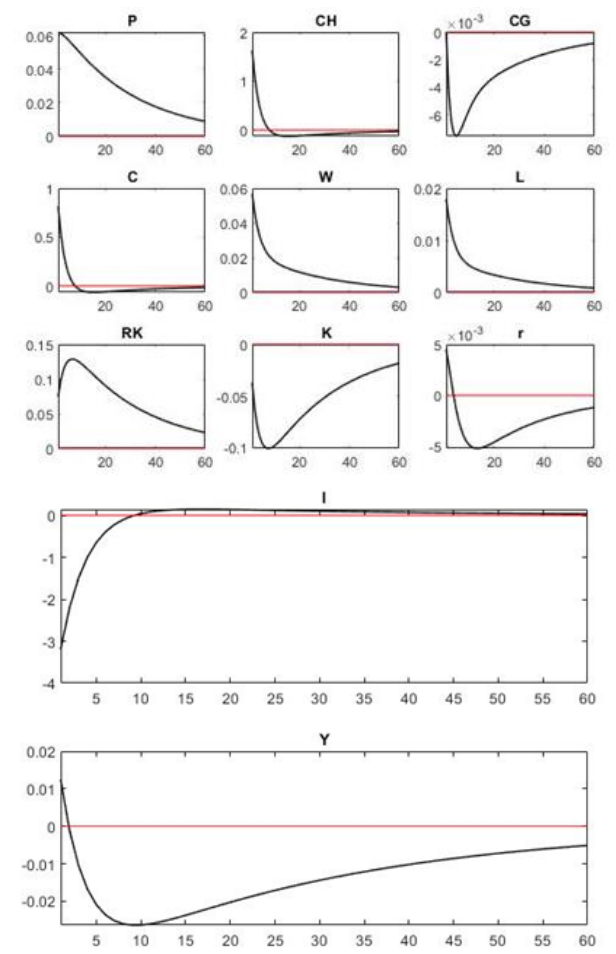

Figure 3: Consumption shock.

\section{Conclusions}

This work is designed to study the effect of fiscal policy, monetary policy, consumption, and technology shock. The major point of interest of this work is to incorporate public goods into the household consumption bundle to learn the reactions of variables within the model to particular shocks. To meet the objective of this work, the simple close economy DSGE model was constructed. The model is then estimated for particular parameters and to discover the effect of each shock on the hypothesis economy by using the data of Thailand. The results of the analysis are consistent with some previous works as already discussed in Section 5.
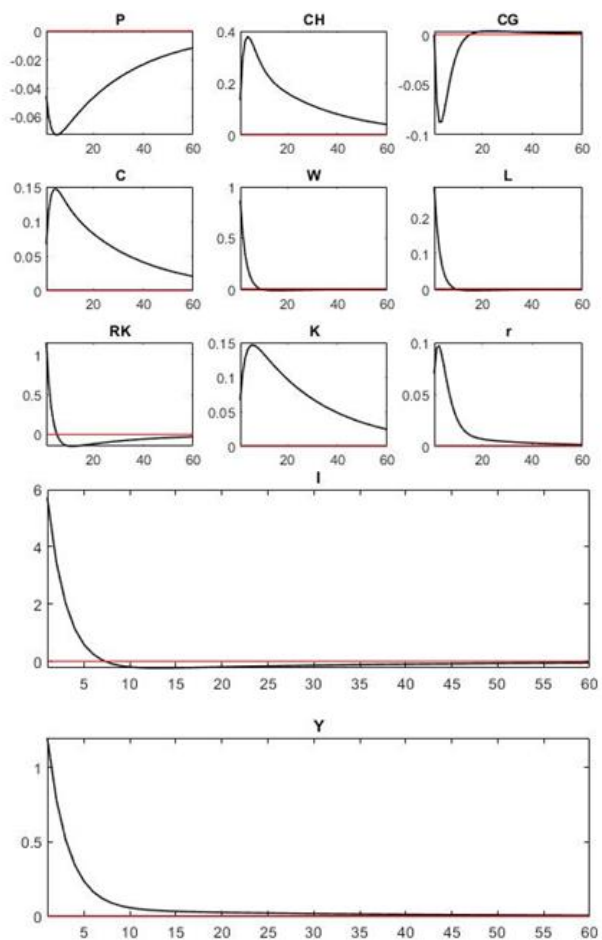

Figure 4: Technology shock. 

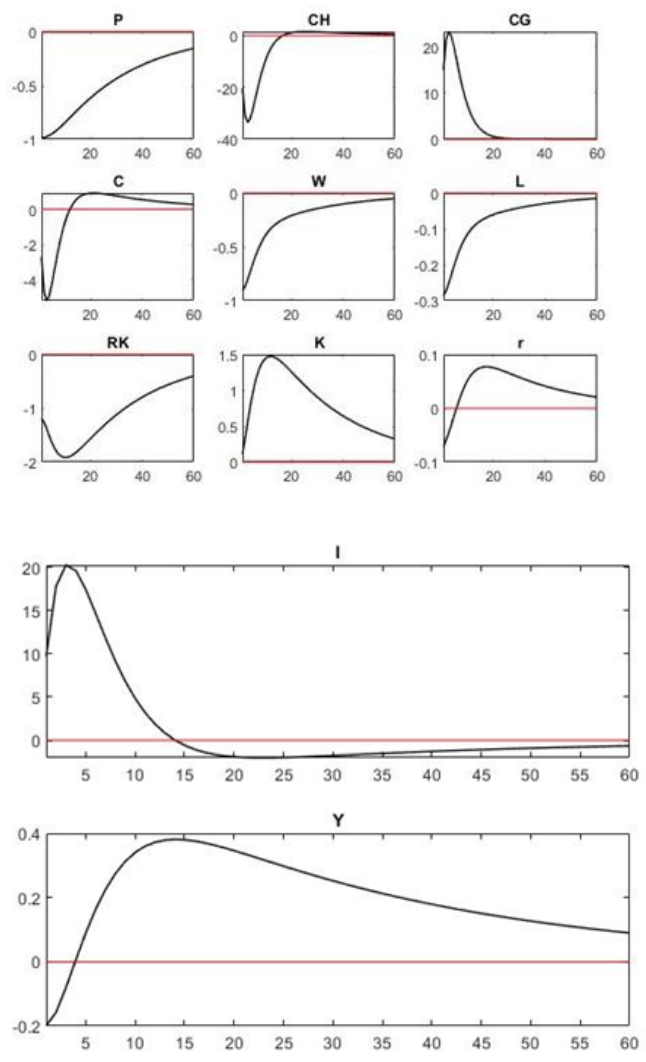

Figure 5: Fiscal policy shock.
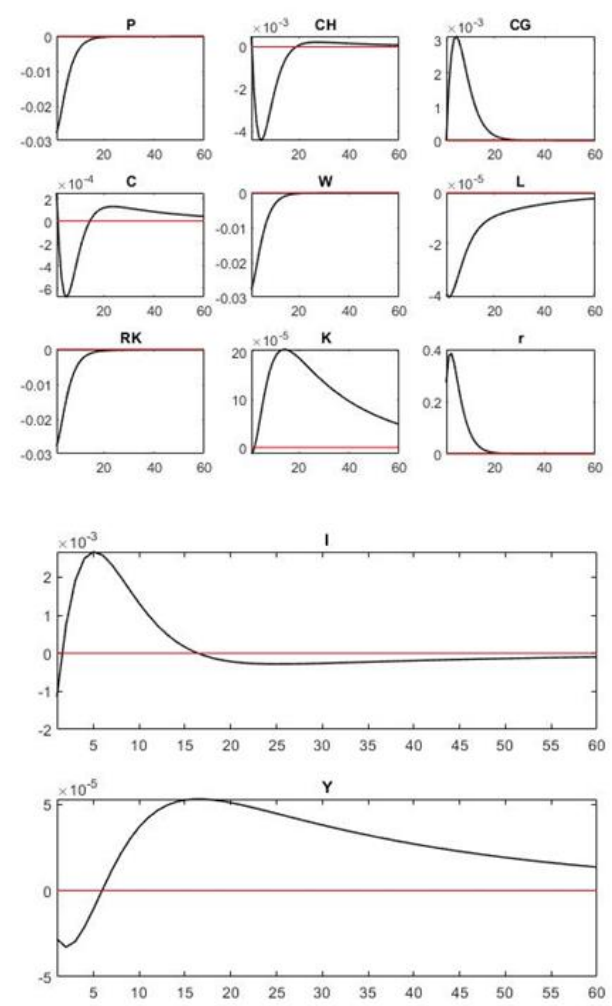

Figure 6: Monetary policy shock

\section{Acknowledgement}

This research is supported by the school of economics, Sukhothai Thammathirat Open University (STOU), Thailand. This work is also supported by the Department of Economics, The University of Central Thailand (UCT), Thailand.

References:

[1] M. Rubio and S. Schuh, Monetary policy and the role of inventory investment, Applied Economics Letters, Vol. 24, No. 21, 2017, pp. 1605-1612.

[2] S. Mouabbi and J. Sahuc, Evaluating the macroeconomic effects of the ECB's unconventional monetary policies," Journal of Money, Credit and Banking, Vol. 51, , No. 4, 2019, pp. 831-858

[3] R. Wang, Unconventional Monetary Policy in Japan: Empirical Evidence from Estimated Shadow Rate DSGE Model, Journal of International Commerce, Economics and Policy ,Vol. 10, , No. 2, 2019, 1950007.

[4] G.-A. Ionita, Monetary policy in a DSGE New Keyesian model-case study for Romania Acta Universitatis Danubius. Economica, Vol. 13, , No. 1, 2017 , pp. 5-16.

[5] W. E. Melesse, Business cycles in Ethiopia under alternative monetary policy rules, African Journal of Economic and Management Studies, 2019.

[6] A. Goyal and A. Kumar 2020 A DSGE model-based analysis of the Indian slowdown, Journal of International Commerce, Economics and Policy, Vol. 11, , No. 1, 2050004.

[7] B. Perry, K. Phillips, and D. E. Spencer, Real wages and monetary policy: a DSGE approach, Journal of Economic Studies, 2015.

[8] A. Nandi, Indian Fiscal Policy: A DSGE 
Primer, The Journal of Developing Areas, Vol. 54, , No. 2, 2020.

[9] C. Jooste and R. Naraidoo, The Macroeconomics Effects of Government Spending Under Fiscal Foresight, South African Journal of Economics, Vol. 85, , No. 1, pp 6885, 2017.

[10] F. O. Bilbiie, Nonseparable preferences, frisch labor supply, and the consumption multiplier of government spending: One solution to a fiscal policy puzzle, Journal of Money, Credit and Banking, Vol. 43, , No. 1, 2011, pp. 221-251.

[11] V. Lewis and R. Winkler, Government Spending, Entry, And The Consumption Crowding- In Puzzle International Economic Review, Vol. 58 , No. 3, 2017, pp 943-972.

[12] G. Coenen and R. Straub, Does government spending crowd in private consumption? Theory and empirical evidence for the euro area, International Finance, Vol. 8, No. 3, 2005, pp. 435-470.

[13] G. J. Natvik, Government Spending Shocks and Rule- of- Thumb Consumers with Steady- State Inequality, The Scandinavian Journal of Economics, Vol. 114, No. 4, 2012, pp. 1414-1436.

[14] G. Corsetti, A. Meier, and G. J. Müller, Fiscal stimulus with spending reversals, Review of Economics and Statistics, Vol. 94 , No. 4, 2012, pp 878-895.

[15] D. Furceri and R. M. Sousa, Does government spending crowd out private consumption and investment? World Economics, Vol. 12, No. 4, 2011, pp. 153-170.

[16] A. Kormilitsina and S. Zubairy, Propagation mechanisms for government spending shocks: A bayesian comparison, Journal of Money, Credit and Banking, Vol. 50 , No. 7, 2018, pp 1571-1616.

[17] M. Lorusso and L. Pieroni, Disentangling Civilian and Military Spending Shocks: A Bayesian DSGE
Approach for the US Economy, Journal of Risk and Financial Management, Vol. 12 no 3, 2019. p 141.

[18] M. Parkin, Macroeconomics 10th Edition. Pearson Series in Economics, 2012.

[19] R. Bade and M. Parkin, Essential foundations of economics Pearson/Addison Wesley, 2013.

[20] G. D. Mateer, L. Coppock, and B. O'Roark 2016 Essentials of economics First Edition. New York: W.W. Norton

[21] J. D. Alba, C. Wai-Mun, and P. Donghyun, Foreign Output Shocks and Monetary Policy Regimes in Small Open Economies: A DSGE Evaluation of East Asia, 2011.

[22] A. Justiniano and B. Preston, Monetary policy and uncertainty in an empirical small open- economy model Journal of Applied Econometrics Vol. 25, No. 1 Art. No 1, 2010.

[23] C. Çebi, The interaction between monetary and fiscal policies in Turkey: An estimated New Keynesian DSGE model Economic Modelling Vol. 29, No. 4, 2012. Pp. 1258-1267.

[24] . Kotera and S. Sakai, Policy Simulation of Government Expenditure and Taxation Based on the DSGE Model Public Policy Review Vol. 14, No 4, 2018, pp. 613-640.

[25] M. H. Alp and S. Elekdag, Shock Therapy! What Role for Thai Monetary Policy? International Monetary Fund, 2012.

[26] Y. Iwata, Fiscal Policy in an Estimated DSGE Model of the Japanese Economy: Do Non-Ricardian Households Explain All? Economic and Social Research Institute, Cabinet Office, 2009.

[27] K. Bhattarai and D. Trzeciakiewicz, Macroeconomic impacts of fiscal policy shocks in the UK: A DSGE analysis, Economic Modelling, Vol. 61, 2017, pp. 321-338.

[28] I. W. Bache, L. Brubakk, and J. Maith, Simple rules versus optimal policy: 
what fits?, 2010.

[29] K. Pakdeesana, Exchange Rate-Based VS Conventional Taylor Rule: A Comparison under DSGE model for Thailand, 2015.

[30] S. Xiaojin and T. K. Ping, 9 What cycles? Data detrending in DSGE models, Studies in Nonlinear Dynamics \& Econometrics Vol. 23, No 3, 2019.

[31] F. Schorfheide, Loss function- based evaluation of DSGE models Journal of Applied Econometrics Vol. 15, No. 6, 2000, pp. 645-670.

[32] D. O. Beltran and D. Draper, Estimating the parameters of a small open economy DSGE model: Identifiability and inferential validity FRB International Finance Discussion Paper, No . 955, 2008.

[33] S. Elekdag, A. Justiniano, and I. Tchakarov, An estimated small open economy model of the financial accelerator, IMF Staff Papers, Vol. 53, No.2, 2006, pp. 219-241.

[34] M. Steinbach, P. Mathuloe, and B. Smit, An open economy New Keynesian DSGE model of the South African economy, South African Journal of Economics, Vol. 77, No. 2, 2009, pp. 207-227.

[35] S. Tanboon 2008 Structural Model for Policy Analysis Monetary Policy Department, The Bank of Thailand.

[36] E. Pytlarczyk, An estimated DSGE model for the German economy within the euro area, Discussion Paper Series 1, 2005 , .

\section{Creative Commons Attribution License 4.0} (Attribution 4.0 International, CC BY 4.0)

This article is published under the terms of the Creative Commons Attribution License 4.0

https://creativecommons.org/licenses/by/4.0/deed.en_US 